\title{
ANALYSIS OF RETRO-ILLUMINATION PHOTOGRAPHS FOR USE IN LONGITUDINAL STUDIES OF CATARACT
}

\author{
M. L. HARRIS, K. J. HANNA, G. A. SHUN-SHIN, R. HOLDEN and N. A. P. BROWN \\ Oxford
}

\begin{abstract}
SUMMARY
Retro-illumination photography has potential for the monitoring of cortical and posterior subcapsular cataract formation. Variations in the individual illumination results have limited accurate quantification of opacities within such images. We present a new image analysis technique which minimises the effect of uneven and varying retro-illumination. The new technique has been tested for variation between photographers and over a short time period. We believe it is of value in lens assessment in combination with a semi-quantitative grading system.
\end{abstract}

Senile cataract can be broadly divided into three types: nuclear, subcapsular and cortical. To follow the development of cataract, measurement of each of these should be repeatable. Slit-image (Scheimpflug) photography is of proven use in biometry of the human lens. ${ }^{1.2}$ Accurate data on nuclear lens changes can be obtained in this way but it is unsuitable for measurement of cortical and subcapsular opacities. ${ }^{3}$ The features of both cortical and subcapsular lens opacities are demonstrated well by retro-illumination photography. ${ }^{4}$ Quantification of the opacities from retroillumination photographs would give a measure of cataract for use in natural history, anti-cataract intervention and toxicity studies.

The technique of retro-illumination photography for recording disorders of the optical media of the eye was described in 1950 by adaptation of a fundus camera. ${ }^{5} \mathrm{~A}$ slit lamp version was presented in 1955 by Fincham and this has been the basis of all further instruments. ${ }^{6}$ The illumination and viewing axes are united by $\mathrm{a} 45^{\circ}$ glass plate. Fincham describes the use of a deep orange filter to reduce the light scattered from opacities and to increase the image contrast. The introduction of crossed polarisers by Kawara and Obazawa reduced the unwanted corneal reflection. ${ }^{7}$ The Oxford retro-illumination camera described by Brown ${ }^{8}$ tackles the problem of image alignment by the introduction of fixation targets at the front of the camera. These are placed at $15^{\circ}$ from the visual axis so that the

Correspondence to: M. L. Harris, Clinical Cataract Research Unit, Nuffield Laboratory of Ophthalmology, Walton Street, Oxford OX2 6AW, UK. optic nerve head, the most reflective part of the normal fundus, becomes the source of retro-illumination in the average eye. The latest Brown design of camera incorporates a $C \mathrm{CD}$ (charged couple device) to give a digital picture output. The last remaining corneal reflection which passes even the best-quality polarisers has been excluded by the introduction of a blocking device in the illumination path. The image acquired is a $512 \times 512$ pixel, $0-255$ grey level picture and can be stored as a computer file on magnetic or optical media.

Despite the progress made in the camera field the pictures which are acquired by the retro-illumination technique show uneven illumination due to the corneal 'Maltese cross' (a polarisation effect). In longitudinal studies there is variability of the retro-illumination. This variability is due to small changes in ocular alignment and to other factors in the eye. The eyes can move in the horizontal or vertical axes or by cyclotorsion; even when fixation is good the eyes are never entirely still. The other factors in the eye are small differences in pupil size on different visits and changes in the cataract affecting fundal illumination. Whilst the introduction of the fixation device has undoubtedly helped, the displacements used are based on the position of the optic nerve head relative to the visual axis in the average eye. Each individual eye will display similar retro-illumination characteristics but treated as a group there is variation. In addition, the lens increases in width with age. It is not practical to have a camera with a depth of focus to include the lens only of each individual eye. The exact focusing of the camera is therefore important in follow-up studies.

In this report we describe the background to and repeatability of a specifically designed image analysis technique which minimises the effect of uneven and of varying retro-illumination.

\section{MATERIALS AND METHODS}

All the images used in this study were acquired with the Oxford CCD retro-illumination camera (Marcher Enterprises, Rotherwas Industrial Estate, Hereford, UK). The camera was focused at the pupil plane. The camera image 


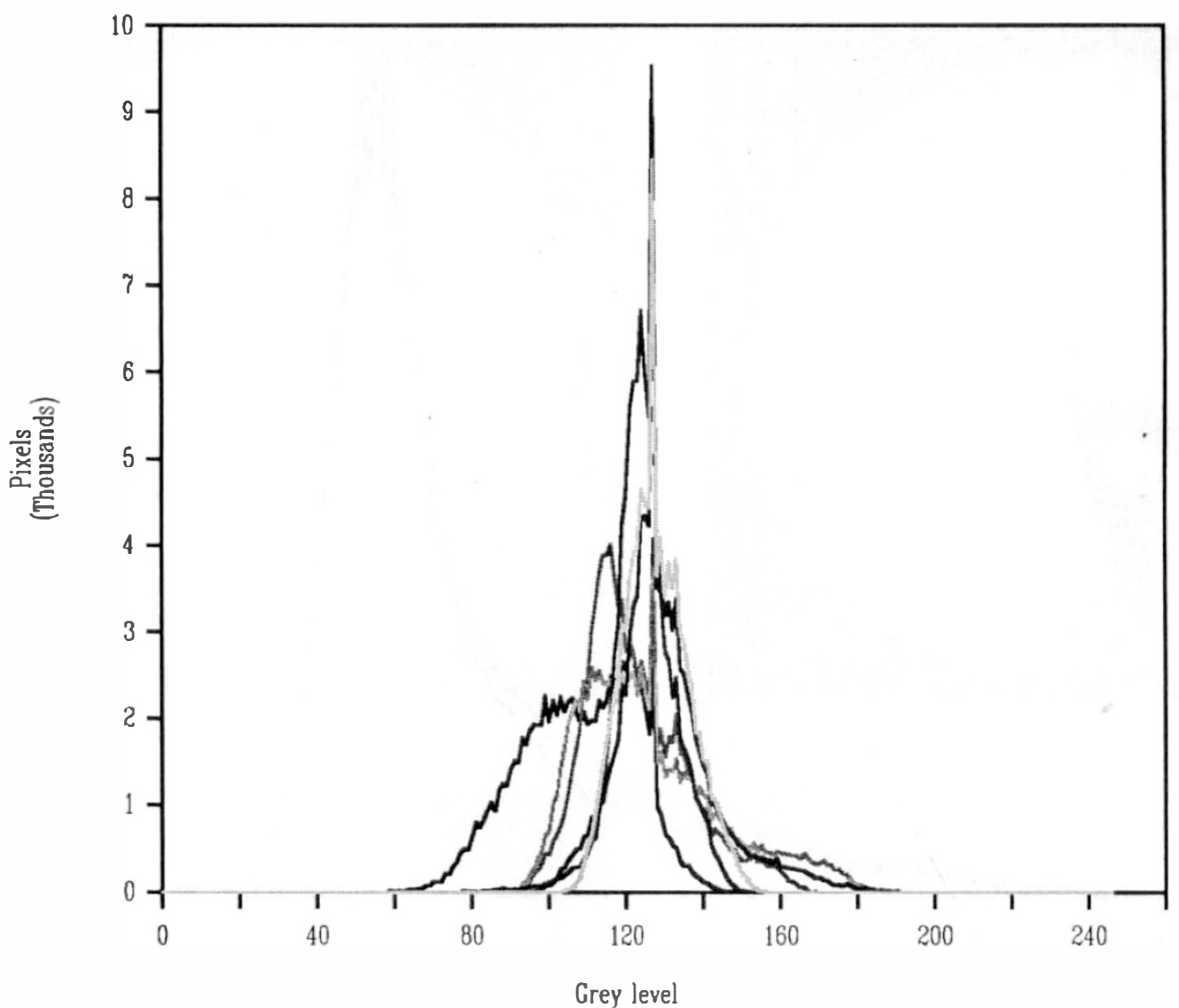

Fig. 1 a.

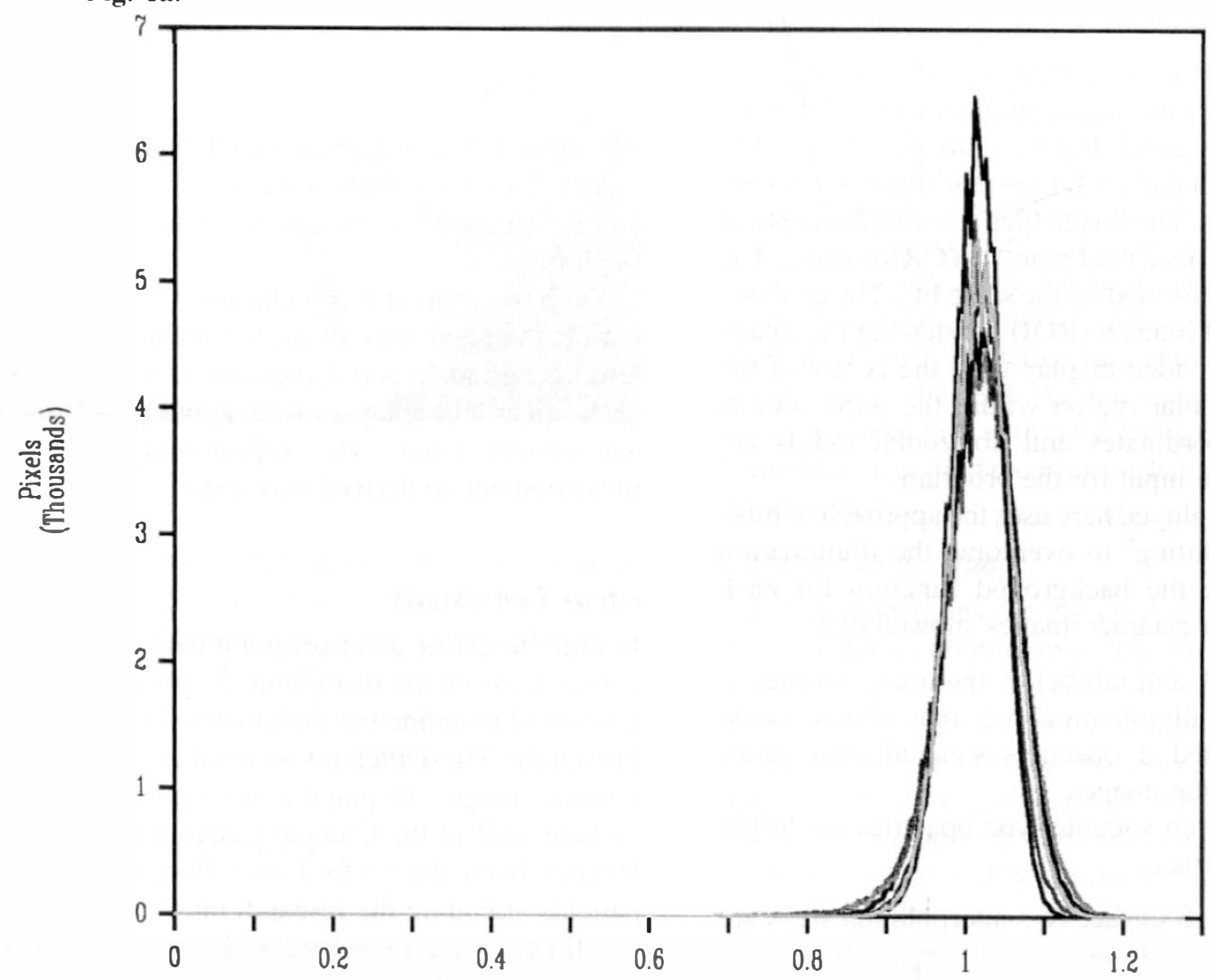

Fig. 1 b.

Fig. 1. (a) Example of six raw histograms to show the grey level distributions in retro-illumination photographs. (b) The same six histograms after application of the illumination compensation algorithm. 


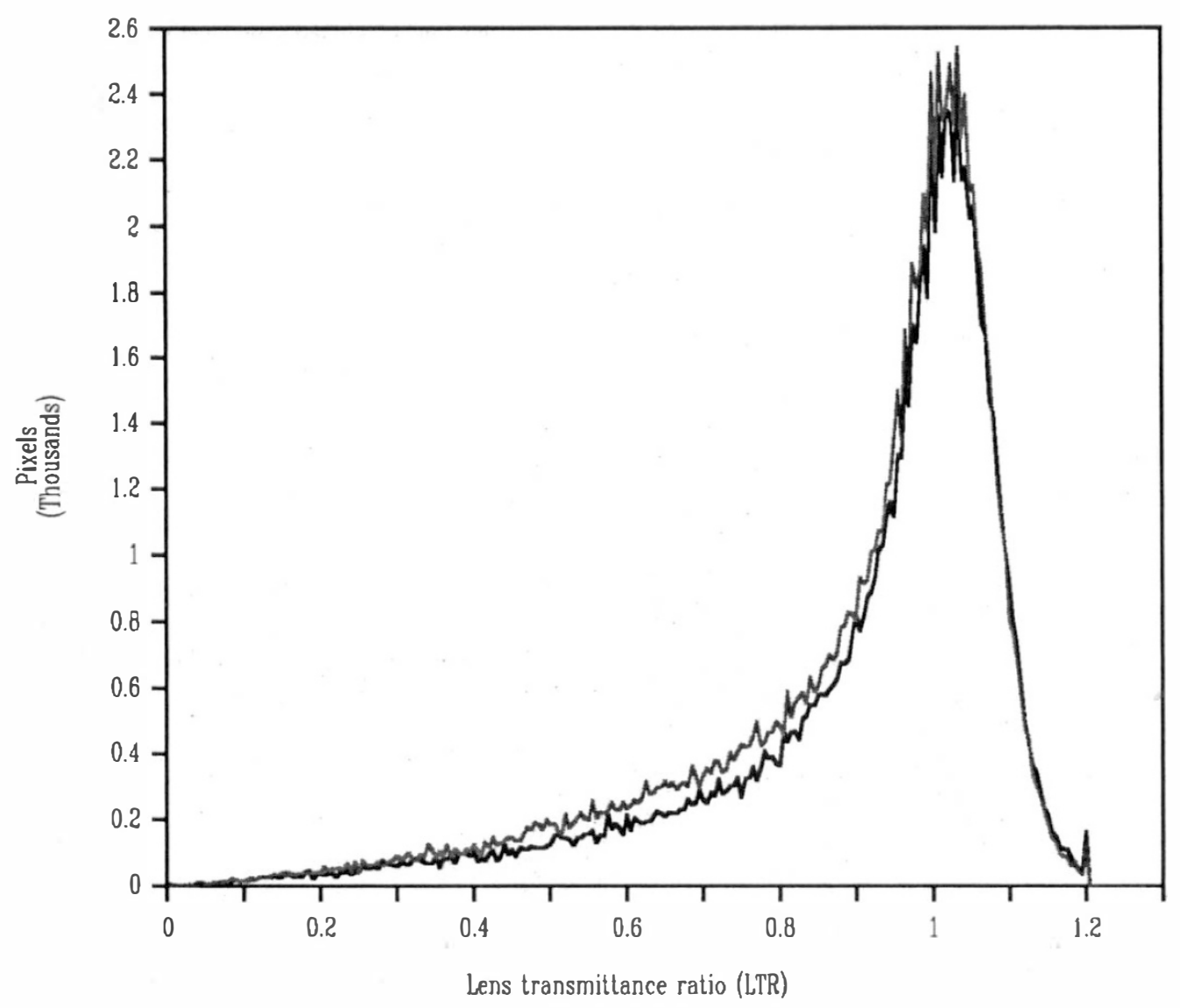

Fig. 2. Processed histograms of two cataract photographs of the same eye taken by different photographers on the same day.

is relayed to a framestore in an IBM-type PC. The image is fixed in the framestore by a frame grabber which functions in one-thirtieth of a second. The fixed image is $512 \times 512$ pixels; using the standard 8-bit system there are potentially 256 grey levels. The image files are stored on optical media using a write once read many (WORM) drive. The image analysis is performed on the same PC. The analyser defines the region of interest (ROI) by viewing the image to be analysed on a video display unit; the centre of the largest possible circular region within the pupil area is found, the $\mathrm{X}, \mathrm{Y}$ coordinates and horizontal radius are defined and form the input for the program.

The algorithm employed here uses the approach of morphological surface fitting ${ }^{9}$ to overcome the illumination problem and define the background function for each image. Inspection of cataract images showed that:

1. Opacities are dark and fall below the image surface.

2. The background illumination (i.e. that which would have been detected if opacities were absent) varies gradually across the images.

3. The reflections from vacuole-type opacities are bright and above the surface.

To define the image surface two interpolation steps are performed, firstly to eliminate the influence of vacuoles and then to close off the cataract regions. These two steps produce a smooth image surface which gives a value for the retro-illumination at each point. The processed image can then be compared with the original image to give the lens transmittance ratio (LTR):

$$
\mathrm{T}_{\text {health }} / \mathrm{T}_{\text {actual }}=\mathrm{LTR}
$$

The output is a histogram of LTR units. ${ }^{10}$ For clinically clear lenses these histograms have a regular distribution and for cataractous images the histograms are skewed to the left.

We have applied this technique in a two-part study. In part 1, the clear lens study, we defined the normal clear lens histogram. In part 2, the cataract lens study, the results of the clear lens analyses were applied to define the cataract cut-off point. The repeatability of the cataract measurement so derived was tested.

\section{Clear Lens Study}

In order to define a cut-off point between clear and cataractous areas of the histogram, 53 clear lens images were processed to define the dimensions of the ideal clear lens histogram. These pictures were taken from a collection of normal images displaying no opacities. The subjects include staff of the Clinical Cataract Research Unit, colleagues from the Oxford Eye Hospital and spouses of patients attending the research unit.

All eyes were examined at the biomicroscope prior to imaging to establish clarity. Grading by the Oxford classification ${ }^{11}$. was performed and all lenses were grade 0 for all cortical and subcapsular features. Nuclear brunescence and white scatter of greater than grade 2 led to exclusion from the clear lens study. 


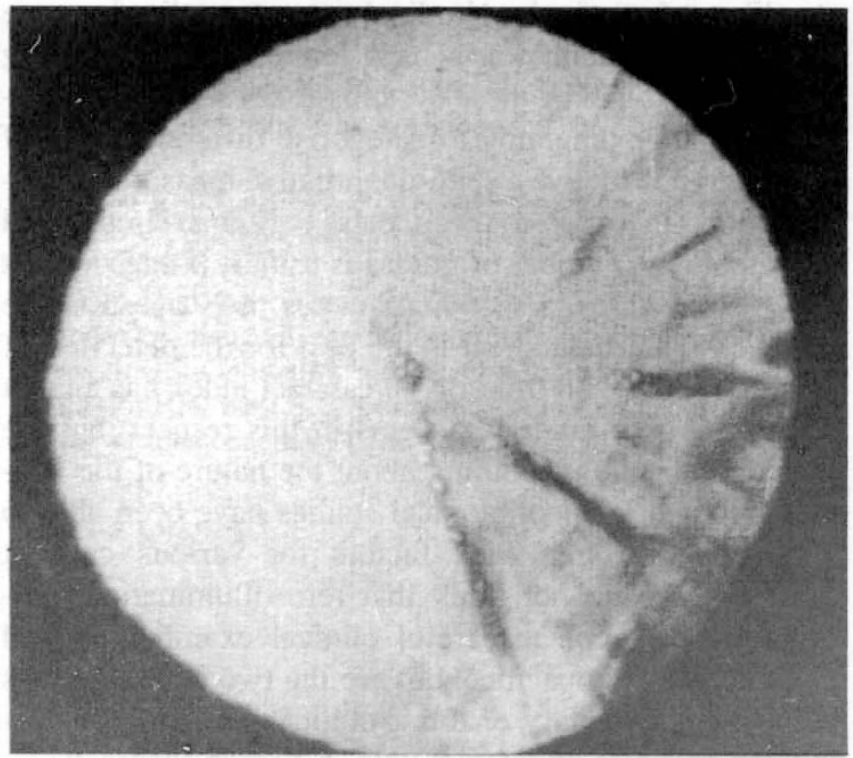

Fig. 3a.

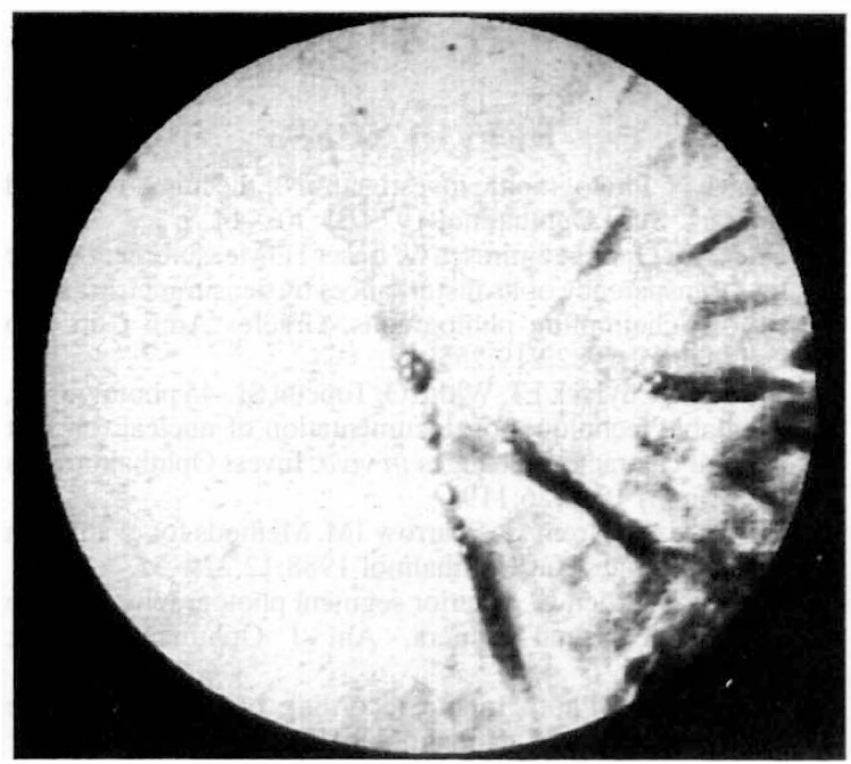

Fig. 3b.

\section{Cataract Lens Study}

To test the repeatability of the analysis 48 pairs of images were analysed by the same method. Twenty-four of the images were taken of cataractous lenses by two photographers on the same day. The subjects sat back from the equipment between photographic sessions. The remaining 24 pairs were photographed at a 3-month interval by the same photographer.

\section{RESULTS}

\section{Clear Lens Study}

Fig. 1 demonstrates the effect of processing on clear lens pictures in a representative sample of six. In Fig. 1a the varying histograms from the original ROIs are shown. In Fig. 1b the histograms for the processed images demonstrate normalisation around the mode illuminance transmission (ILT) ratio of 1; values above and below the mode

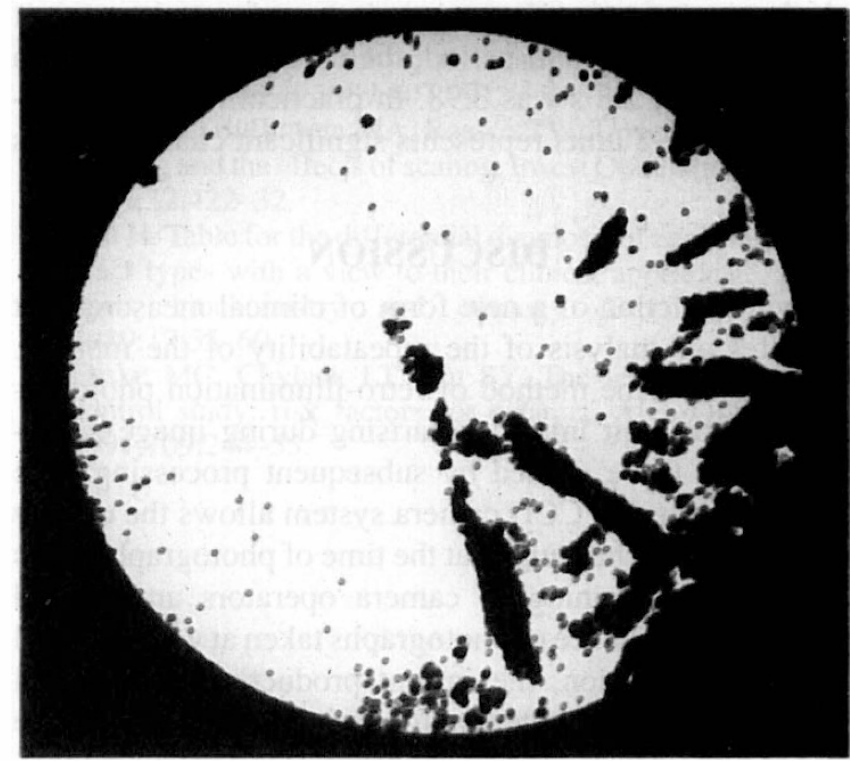

Fig. 3c.

Fig. 3. (a) Digital image as stored direct from camera. Note the uneven background illumination. (b) The same image after illumination compensation. (c) Computer decision on the cataractous areas of the photograph.

represent noise in the system, including the 'Maltese cross' polarisation effect. To define a cut-off point for the following cataract analysis, the distance from the mode to the point where the pixel count fell below 100 was found for each of the 53 processed histograms. The mean and standard deviation for this measurement was calculated (mean $=0.130, \mathrm{SD}=0.027$ ). The cut-off point was defined as: group mode of the processed histograms + mean measurement to the 100 pixel level $+1.67 \times$ standard deviation of that measurement, i.e. $95 \%$ level on a one-tailed probability test. In the calculations performed on the cataract histograms all pixels beyond this level are defined as cataract and expressed as a percentage of the ROI. As this value is not the total percentage of opacities within the lens (part of the lens always being hidden behind the iris), we have called this value the cataract index.

\section{Cataract Lens Study}

Fig. 2 demonstrates the effect of image processing on a pair of cataract photographs. The processed histogram is no longer a regular distribution but, typically as here, shows skew to the left. Fig. 3a and $3 b$ show one of the equivalent images before processing and after illumination compensation, respectively; Fig. $3 c$ shows the areas which the computer defines as cataract.

To test the variability we chose to use the coefficient of variation and have also calculated the measurement error of the system under each set of circumstances. ${ }^{12}$ The coefficient of variation for the 24 pairs taken by different photographers during the same session was $5.95 \%$. The measurement error for the system, expressed as the value below which the difference between the two measurements will lie with a probability of $0.95(2.8 \mathrm{~s})$ is 1.51 . For 
the between-session data, assuming no change in cataract index over a 3-month period, the coefficient of variation was $15.83 \%$; $2.8 \mathrm{~s}$ was 3.98 . In practical terms a difference of $>3.98$ units represents significant change by this method.

\section{DISCUSSION}

The introduction of a new form of clinical measurement requires an analysis of the repeatability of the method. Variations in the method of retro-illumination photography can be split into those arising during image acquisition and those caused by subsequent processing. The development of a CCD camera system allows the quality of the image to be gauged at the time of photography. This helps in the training of camera operators and should reduce the incidence of photographs taken at varying focal planes. In addition, the instant production of a digital image removes the potential for variation arising from the use of film (lack of constancy of supply and development). Long-term storage of images in digital format is more reliable and convenient than storing processed film. All these factors make the CCD camera system a more satisfactory method of image acquisition. Our between-session variations suggest that there is significant variation occurring with time in the image acquisition system. The camera system runs off a stabilised power supply and the reliability of the standard PC computer is well established. However, the CCD receiver is sensitive to alterations in room temperature. During the period of this study the system was calibrated on a weekly basis; we now routinely calibrate the system prior to each photographic session, and a software subroutine has been incorporated to make this easier.

Previous techniques for the analysis of retro-illumination have usually depended upon the operator defining the clear lens areas. They have varied in complexity from manual grid counting methods to interactive computer analysis techniques. The global histogram technique described by Maclean and Taylor ${ }^{13}$ has been improved by dividing the ROI into grids that are either square ${ }^{14}$ or segments of a circle. ${ }^{15}$ Sparrow, working in this unit, produced a repeatable automated technique. ${ }^{16}$ His images taken with the film using retro-illumination camera were digitised by a CCD camera over a Bowen's illumitran. ${ }^{17}$ We found that working with the live CCD images produced by the latest generation of cameras this algorithm was no longer applicable. The current algorithm is designed to minimise the operator interaction and leave the computer to calculate the area of cataract in the image. The operator has only to define the ROI, which is performed easily and quickly using a computer mouse; this represents the only remaining processing variable. We are currently working on a way to register (superimpose) follow-up photographs by converting the OLIVIA algorithm $^{18}$ to $\mathrm{PC}$ usage, and expect that this will reduce variation further.

The cataract lens study demonstrates a repeatable method sensitive to a change. The alternative to photo- graphic analysis for longitudinal cataract studies is to use a grading system, of which there are a growing number. ${ }^{10,19,20}$ All of these systems use a series of photographs and/or diagrams to categorise different types of lens opacities to give a semi-quantitative measure of opacification. In order to keep these systems simple and repeatable the number of grades is usually 4 or 5 . Whilst very useful in cross-sectional studies, it is questionable whether this arrangement is the best for the detection of small changes with time. ${ }^{21}$ The cataract index has a great advantage over grading systems in this respect, but the index alone tells us nothing about the nature of the opacities. Recent epidemiological studies have been able to distinguish different risk factors for various cataract types. ${ }^{22.23}$ We do not think that retro-illumination photography can replace careful clinical examination and classification of opacities, but see the two approaches as being complementary, enabling clinical researchers to follow the progress of cataract with increased accuracy.

Key words: Cataract, Clinical measurement, Photography, Progression analysis.

\section{REFERENCES}

1. Brown N. Photographic investigation of the human lens and cataract. Surv Ophthalmol 1979;23:307-14.

2. Hockwin O, Dragomirescu V, Laser H. Measurement of the lens transparency or its disturbances by densitometric analysis of Scheimpflug photographs. Graefes Arch Clin Exp Ophthalmol 1982;219:255-62.

3. Chen SY, Chylack LT, White O. Topcon SL-45 photography, a suitable technique for documentation of nuclear, but not cortical cataractous changes in vivo. Invest Ophthalmol Vis Sci (Suppl) 1985;26:119.

4. Brown NAP, Bron AJ, Sparrow JM. Methods for evaluation of lens changes. Int Ophthalmol 1988;12:229-35.

5. Douvas N, Allen L. Anterior segment photography with the Nordenson retinal camera. Am J Ophthalmol 1950; 33:291-8.

6. Fincham EF. Photographic recording of opacities of the ocular media. Br J Ophthalmol 1955;39:85-90.

7. Kawara T, Obazawa H. A new method for retro-illumination photography of cataractous lens opacities. Am J Ophthalmol 1980;90:186-9.

8. Brown NAP. The Oxford retro-illumination cataract recording camera: a new instrument. J Audiovis Med 1988;11:58-60.

9. Haralick RM, Sternberg A, Zhuang XH. Image analysis using mathematical morphology. IEEE Transaction on Pattern Analysis and Machine Intelligence (PAMI-9): 1987;532-50.

10. Hanna KJ. Monitoring cataract change. DPhil thesis, Oxford, 1990.

11. Sparrow JM, Bron AJ, Brown NAP, Ayliffe W, Hill AR. The Oxford clinical cataract classification and grading system. Int Ophthalmol 1986;9:207-25.

12. Bland M. An introduction to medical statistics. Oxford: Oxford University Press, 1989:276-8.

13. Maclean H, Taylor CJ. An objective staging for cortical cataract in vivo aided by pattern-analysing computer. Exp Eye Res 1981;33:597-602.

14. Miyauchi A, Mukai S, Sakamoto Y. A new analysis method for cataractous images taken by retro-illumination photography. Ophthalmic Res 1990;22 (Suppl):74-7. 
15. Wolfe JK, Chylack LT. Objective measurement of cortical and subcapsular opacification in retroillumination photographs. Ophthalmics Res 1990;22 (Suppl):62-7.

16. Sparrow JM. The lens in diabetes. DPhil Thesis, Oxford, 1988.

17. Sparrow JM, Brown NAP, Shun-Shin GA, Bron AJ. The Oxford Modular Cataract Image Analysis System. Eye 1990;4:638-48.

18. Shun-Shin GA, Hanna KJ, Bron AJ, Brown NAP. A new index of change in cataract morphology using image analysis. Invest Ophthalmol Vis Sci 1989;30(Suppl):329.

19. Taylor HR, West SK. A simple system for the clinical grading of lens opacities. Lens Res 1988;5:175.
20. Chylack LT, Leske MC, McCarthy D, Khu P, Kashiwagi T, Sperduto R. Lens opacity classification system II (LOCSII). Arch Ophthalmol 1989;107:991.

21. Bailey IL, Bullimore MA, Raasch TW, Taylor HR. Clinical grading and the effects of scaling. Invest Ophthalmol Vis Sci 1991;32:422-32.

22. Pau H. Table for the differential diagnosis of age related cataract types with a view to their clinical appearance, prognosis biochemistry and etiology. Dev Ophthalmol 1989;17:55-60.

23. Leske MC, Chylack LT, Wu SY. The lens opacity casecontrol study: risk factors for cataract. Arch Ophthalmol 1991;109:244-55. 